\title{
Ergebnisse der Schutzimpfungen an der Impfstelle des Zentralkomitees der Preußischen Landesvereine vom Roten Kreuz in Berlin.
}

(Leiter: Geh. Sanitätsrat Dr. K. Beerwald.)

Von Dr. O. Salomon und Dr. R. Weber.

Als Impfstoffe gelungten ausschlioßlich zur. Verwendung die Pookenlyuphe von der Kgl. Impfanstalt zu Berlin, der Typhusimpfstoft voin Institut für Infektionskrankheiten ",Robert Koeh" (Stamn Washington, Abtötumgstemperatur 54 ${ }^{\circ}$, Daner $11 / 4$ Stunde, versetzt mit $0,25 \%$ Trikresol) und der Cholerainpfstoff von der Kaiser Wilhelm-Akademie zil Borlin (Stanun Bakı, Abtötungstemperatur 53 55 *, 70 Minuten, versetzt mit 0,5 Pferol). Letzterer hatte vor anderen Choleraimpfstoffarten den Vorzug, daß er keine Fadell- und Floekenbildung zeigte und sich leicht anfsehntteln ließß. Die Ausfïhrung der Pockenimpfung erfolgte nit Platin-Iridium-Lanzetten, der Typhus- und Choleraimpfung mit Rekordspritzen und Nickelkauülen. Die Desinfektion der Impfstelle, welehe in der übliehen Weise in der Mitte zwischen Sternum und Manilla gewält wurde, geschah mit Aether oder $10 \%$ iger Jodtinktur. Dic Impfungen fanden in der Reihenfolge statt, daß am orsten Tage die Pocken- und die erste Typhusimpfung $(0,5 \mathrm{com})$ verabfolgt wurde; nach sieben Tagen erfolgte die Nachschau und dic zweite Typhusimpfung $(1 \mathrm{ccm})$, wiederum nach aieben Tagen die dritte Typhusimpfung (1 cein). Nach einem Zwischenraum von einer woiteren Woche wurde dic erste Choleraimpfung $\mathbf{0 , 5}$ verabfolgt, an die sich dann nach sieben Tagen die zweite Choleraimpfung 1,0 ansehloß. Innerhalb der folgenden Woche hatte der Geinpfte sich zwecks Nachschan der Inufstelle vorzustellen; nun erst wurde der Inıpsschein unterfertigt. Dadurch, daß die Unterschrift des Impfarztes erst am letzten Nachschautermin erteilt wurde, konnte eine ständige Ueberwachung der Geimpften regel. mäßig gesichert worden. Von dieser Reihenfolge wurde nur in dringenden Fällen abgewichen, wein es sich um äußerst eilige Anforderungen des Personals seitens der Militärbehörde handelte. Dann wurde der Zwisohenraum anf drei bis funf Tage herabgesetzt; dagegen wurde er um aeht bis 14 Tage verlangert, weml sich eine reebt starke Pookenreaktion eingestellt hatte. 
Ueber den Gang der I $m p f u n g$ und über die Verhaltungsmaßregeln wurde das geimpfte Personal in der ersten Zeit mindlich, später dureh ein gedruektes Formular unterriehtet, dessen Inhalt folgender ist: Zur Beaohtung! Jede Impfung ist vor ihrer Ausführung, sowohl auf dem Impfschein wie auch im Protokollbueh einzutragen. Die einzelnen Impfungen finden in Zwischenräumen von fünf bis sieben Tagen statt, und zwar gegen Typhus dreimal, gegen Cholera zweimal und gegen Pocken einmal. Von dieser Regel wird nur in dringenden Fällen abgewichen. Nach erfolgter Typhus- und Choleraimpfung soll innerhalb der ersten 24 Stunden kein Alkohol genossen werden. Treten nach der Poekenimpfung Entzuindung, Sehwellung oder starkes Jucken der Inpfstelle auf, so sind feuehte Umschlage mit verdünnter essigsaurer Tonerde angezeigt. Diese Erscheinungen verschwinden aber in kurzer Zeit auch von selbst. Auf jeden Fall ist das Kratzen und Scheuern der Impfstelle zu vermeiden. Die Wirkung der jedesmaligen Impfung ist zu Protokoll zu geben, entweder gelegentlich der nächsten Impfung, oder, wenn es sich um die letrte Impfung handelt, am nächsten Impftage. Alsdann erfolgt die Beseheinigung des Impfarztes.

Bezüglich der Pockenimpf ung ist zu erwähnen, daß seit Führung der Liste 2873 Personen innerhalb des ersten Kriegsjahres geimpft wurden. Hiervon waren ungefähr 417 nicht zur Nachschau erschienen ohne Erfolg geimpft 101. Die starke Reaktion war hauptsăehlieh bei Personen, welche 30 Jahre und älter waren, zu beobuchten, und zwar waren die Reaktionen dieser Personen größtenteils noch stärker als beim Erstimpfling. Häufig hatten sich bei ihnen von der Impfblatter aus in der nłkehsten Umgebung derselben kleine sekundäre Pustelchen gebildet, soda B der Rand der Impfblatter ein himboerartiges Aussehen bot. An dieser Stelle soll nicht des Näheren auf die Pockenimpffrage eingegangen werden; doch möge die Erwägung angedeutet sein, ob nicht auf Grund dieser zahlreichen Erfahrung eine Wiederinpfung im Alter von 25 bis 30 Jahren bei den Personen gerechtfertigt oder geradezu erforderlich erscheint, welche nicht wieder in 21. Jahre gelegentlich ihrer Militärzeit geimpft worden sind, zumal gerade hinsirhtlich der gefährlieheı Pockenseuche dieser Krieg recht große Gefahren mit sich bringt.

Bei der Typhusimpf ung wurde von der dreimaligen Injektion nicht abgewiehen, da der häufigeren Wiederholung ein größerer innuuısatoriseher Wert beizumessen ist als der höheren Dosis. In den Fällen, bei denen sich starke Reaktioneu zeigtell, was regelmá Big bei Potatoren zu beobachten war, wurdo teils die Dosis verkleinert, teils der Zwisehenraum von 8 auf 14 Tage ausgedehnt, teils ein älterer Impfstoff genommen, weleher erfahrungsgemäB schwhichere Reaktionen muchte. Es wurden im ganzen 2869 Personen geimpft. Hochgradige Reaktionen, wie sie im Schützengraben, in den Garnisoneu ete. bei den Soldaten beobachtet sein sollen, welehe sich in mehrere Tage anhaltendem starken Fieber, verbunden mit Bettlägerigkeit, stärkerer ödematöser Schwellung der Impfstelle und ihrer Umgebung äußertell, wurden bei uns niemals festgestellt.

Ein gleichfalls außerordentlich befriedigendes Resultat hinsichtlich der Reaktion zeigten auch unsere Choleraimpfungen, zumal ein leicht aufschüttelbarer homogener Impfstoff benutzt wurde, wie ja überhaupt die Choleraimpfung allenthalben reeht gut vertragen wird. Geimpft wurden 1606 Personen.

Es ist Gelegenheit genommen worden, das Blut der Geimpften auf seine serologisehe Beschaffenheit hin zu untersuchen.

Die Agglutination ergab bei Typhusgeimpften in etwa $16,6 \%$ der untersuchten Fälle einen Titer von 200 , bei $33,3 \% 150$, bei $16,6 \%$ 100 , bei $22,5 \% 50$ und bei $11,5 \%$ war gar keine Agglutination nach zuweisen.

Bei den Cholerageimpften ergab die Agglutination bei etwa 6,6\% einen Titer von 800 , bei $13,3 \% 400$, bei $6,6 \% 200$, bei $13,3 \%$ \% 100 , bei $6,6 \% 50$, bei $20 \% 50$, bei $33,3 \%$ war nichts nachweisbar. Der Pfeiffersehe Versuch bei den Cholerageimpften ergab folgendes Resultut:

Mit 0,01 Serum wurde eine Oese hochvirulenter Cholerakultur verrieben und intraperitoneal injiziert. In 42,8 Füllen war Schutz nachweisbar, der übrige Teil der Tiere erlag der Infektion. Zu erwähnen wäre noch, daß der agglutinatorische Wert in einem Falle von 400, wie er aeht Tage nach der Impfung nachweisbar war, in 14 Tagen auf 800 gestiegen war, um in vier Woehen wieder auf $400 \mathrm{zu}$ fallen. Eine weitere Beobachtung des.Geimpften war leider nicht möglich. 